\title{
João de Barros Barreto: um construtor do debate organizacional em saúde no Brasil
}

\author{
João de Barros Barreto: a builder of the organizational debate \\ on health in Brazil
}

Carlos Henrique Assunção Paiva (https://orcid.org/0000-0002-7478-9628) ${ }^{1}$

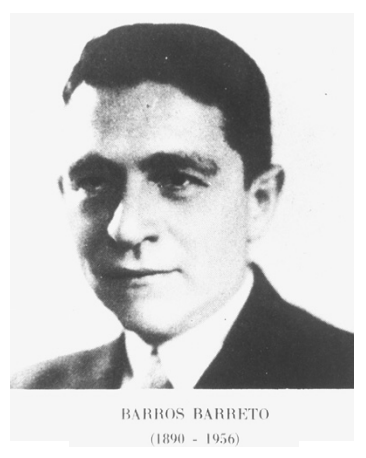

Fonte: Inventário do Instituto Oswaldo Cruz. Departamento de Arquivo e Documentação da Casa de Oswaldo Cruz/Fiocruz (sem data).

\begin{abstract}
The article explores João de Barros Barreto's ideas and proposals for the field of the organization of health services in Brazil. Based on the proposal of the Capanema Reform (19371941), the text reveals the context of the formulation of the so-called district health model in Brazil historically, focusing on its logic, conceptual and theoretical principles and resources employed. The conclusion drawn is that Barros Barreto's professional career, contextualized in a specific scenario of ideas, state agenda and organizational perspectives, contributed decisively to the constitution of modeling achievements of relevant organizational arrangements in the trajectory of Brazilian public health.
\end{abstract}

Key words History of public health, History of the organization of health services, Capanema Reform, João de Barros Barreto
Resumo $O$ artigo explora ideias e propostas de João de Barros Barreto para o campo da organização dos serviços de saúde no Brasil. A partir da proposição da Reforma Capanema (1937-1941), o texto constrói historicamente o contexto da formulação do chamado modelo distrital em saúde no Brasil, com foco em sua lógica, bases conceituais e teóricas e recursos empregados. Concluise que a trajetória profissional de Barros Barreto, contextualizada em um cenário específico de ideias, de agenda de Estado e de perspectivas organizacionais, colaborou decisivamente para a constituição de realizações modeladoras de um arranjo organizacional importante na trajetória da saúde pública brasileira.

Palavras-chave História da saúde pública, História da organização dos serviços de saúde, Reforma Capanema, João de Barros Barreto 


\section{Introdução}

O contexto histórico que dá sequência à Primeira República só mais recentemente tem recebido a atenção sistemática de estudiosos do campo da saúde pública. Esses diferentes estudos têm revelado certo protagonismo do recém-criado Ministério da Educação e Saúde Pública (1930), sobretudo sob a liderança de seu mais importante e longevo ministro, o mineiro Gustavo Capanema (1900-1985), tanto na formulação quanto na implementação de políticas de saúde de caráter nacional. Outrora identificado como um ministro e uma pasta consagrada pelas realizações no campo educacional ${ }^{1,2}$, hoje, graças a uma renovada historiografia ${ }^{3-6}$, as realizações no campo da saúde do período Vargas também ganham o seu lugar na história da saúde pública brasileira.

Ao atentarmos para a trajetória de figuras como Geraldo Paula Souza, Rodolfo Mascarenhas e João de Barros Barreto, só para citar alguns, poderemos também atestar o vigor das ideias e iniciativas no campo sanitário naqueles anos 1930 e 1940. O último, objeto de nosso texto, foi um médico-sanitarista carioca nascido em 1890, peça fundamental para compreendermos as mudanças pelas quais passará a organização da saúde pública brasileira a partir do final dos anos 1930. Não foram mudanças pontuais e efêmeras, em boa medida, Barros Barreto esteve na liderança da mais importante reforma da saúde pública da primeira metade do século passado.

No presente artigo exploraremos algumas ideias e propostas de Barros Barreto, especialmente no ambiente da reforma que ganharia o nome do ministro a que este esteve subordinado: respectivamente a chamada Reforma Capanema e o ministro Gustavo Capanema. Menos de um ano após assumir o Ministério, em 1935, Capanema propõe uma reforma geral na organização da saúde pública nacional. Seu primeiro ato, posto em prática com base na Lei $n^{\circ} 378$, de janeiro de 1937, envolveu uma vigorosa revisão na estrutura político-administrativa do Ministério, a partir de então denominado Ministério da Educação e Saúde (MES). Um segundo importante movimento viria cerca de 4 anos depois, quando o ministro se voltou, segundo nos informa Hochman $^{3}$, mais especificamente para as ações de saúde.

Na direção do Departamento Nacional de Saúde (DNS), órgão diretamente subordinado ao ministro, Barros Barreto permitiu que orientações políticas mais gerais do governo, sobretudo no que se refere ao fortalecimento da capacidade de intervenção da União, tivessem correspondência nos assuntos da saúde. Ao formular e conduzir a reforma na saúde, o chefe do DNS produziu uma centralização normativa em torno do executivo federal e a criação de serviços verticais centrados em doenças especificas ${ }^{3,6}$. Adicionalmente, o mesmo conjunto de reformas administrativas permitiu a criação de uma estrutura organizacional do tipo distrital como uma forma de melhor oferecer a prestação da saúde pública no país ${ }^{5,7}$. Ambos os movimentos representaram, sem dúvida, uma maior presença do governo federal no território nacional.

Os distritos sanitários, tal como concebidos por Barros Barreto ${ }^{8-10}$, permitiriam um primeiro arranjo nacional de organização da oferta dos serviços de saúde segundo critérios territoriais e populacionais. Por intermédio de instâncias como as Delegacias Federais de Saúde e as Conferências Nacionais de Saúde foi concebida uma articulação entre instituições de saúde federais, estaduais, municipais e privadas, na presente escala, sem precedentes na trajetória da organização da saúde brasileira.

Em um desenho institucional que, do ponto de vista estritamente organizacional, mantem relativa semelhança com os arranjos modernos de organização da atenção à saúde com base na Atenção Primária à Saúde, Barros Barreto, assim como diferentes gerações de sanitaristas que atuaram no período 1920-1940, entenderam que os centros de saúde poderiam servir como instituições organizadoras do fluxo de serviços e procedimentos diagnósticos e terapêuticos no interior de um distrito sanitário. Para tal, o médico chegou a conceber a existência de um sistema de "cartas" entre clínicos que pudesse impor alguma racionalidade para o "bom serviço" dos produtos e serviços diagnósticos previstos no interior dos distritos de saúde ${ }^{10}$.

Desta forma, a experiência de organização distrital dos anos 1930-1940, a que a trajetória de Barros Barreto se encontra ligada, revela que o debate organizacional e o processo efetivo de implantação de políticas nacionais de saúde, como arenas para onde convergiram diversos enunciados relativos às práticas profissionais e gerenciais, tem na trajetória brasileira um contexto e personagens de destaque naquele período.

Sem perder de vista tal horizonte de questões, o presente texto procurará explorar algumas ideias e propostas de Barros Barreto como uma forma de examinar algumas das matrizes do pensamento organizacional em saúde no país. Nosso foco recairá na formulação, via Reforma Capane- 
ma, do chamado modelo distrital em saúde no Brasil, centrando nossa atenção em sua lógica, bases conceituais e teóricas e recursos empregados.

Sem perder de vista, portanto, a trajetória de Barros Barreto, discutiremos suas ideias e propostas, com foco nas questões organizacionais do aparato institucional da saúde brasileiro. Para tal, organizamos o texto em 3 partes. Na primeira parte, com a finalidade de oferecer alguns elementos de um marco contextual mais amplo, apresentamos nosso protagonista no contexto em que este se encontra inserido. Parece-nos importante que o leitor compreenda que as ideias e propostas de Barros Barreto eram partes de mudanças gerais na organização do Estado brasileiro. Na sequência, na parte 2, sempre no escopo da reforma, nos aprofundaremos no debate e nas iniciativas organizacionais relativas ao setor da saúde. A partir daí, na última parte, construímos a atividade de Barros Barreto à frente da Reforma Capanema.

Sendo assim, não é nosso propósito fazer uma "história de vida" do personagem, mas contextualizar alguns elementos de seu pensamento e empreendimentos em um cenário específico, cujas realizações serão modeladoras de um arranjo organizacional para a saúde pública brasileira. $\mathrm{Na}$ última parte do texto, convidamos o leitor para à conclusão do artigo.

\section{Barros Barreto: protagonista e filho do seu tempo}

João de Barros Barreto formou-se pela Faculdade de Medicina do Rio de Janeiro, em 1912. Cerca de seis anos depois concluiu curso de aperfeiçoamento no Instituto Oswaldo Cruz, em Manguinhos. Nas norte-americanas Johns Hopkins School of Hygiene and Health e na Harvard School of Public Health, por volta de meados dos anos 1920, complementaria sua sólida formação como sanitarista.

Àquela altura, a formação nos Estados Unidos representou para Barros Barreto e outros médicos brasileiros o contato com "ideias novas", que conectavam a medicina à saúde pública. A importância atribuída ao centro de saúde como uma unidade sanitária nucleadora de ações de cura, de acompanhamento e de prevenção de doenças mais prevalentes, com importante destaque para as ações de educação sanitária em um dado território, eram parte fundamental das propostas e da formação profissional oferecida por instituições de ensino e pesquisa norte-americanas, com destaque às duas acima mencionadas.
É verdade que a influência anglo-saxã na formação profissional em saúde no Brasil não se restringiu às viagens de brasileiros aos Estados Unidos. Segundo nos refere Lima e Fonseca ${ }^{11}$, tanto a criação do Instituto de Higiene de São Paulo quanto os cursos de saúde pública oferecidos pelo Instituto Oswaldo Cruz, no Rio de Janeiro, sobretudo a partir de 1930, se aproximavam em muitos aspectos das propostas de profissionalização oferecidas nos Estados Unidos. A rigor, ambos davam conta de questões e preocupações já razoavelmente debatidas em fóruns internacionais de saúde pública do período.

Uma formação profissional sólida, em sintonia com a agenda internacional, foi o passaporte de Barros Barreto para construir uma ampla experiência à frente da burocracia pública da saúde no Brasil. Ele serviu como diretor de Saneamento Rural no Pará (1920) e no Paraná (1921-1924); serviu como assistente do Diretor geral do Departamento Nacional de Saúde (1926-1929) e foi diretor do Departamento de Saúde do Estado de São Paulo (1931). Destaque, como já sinalizamos, para o mais alto cargo da saúde pública abaixo do ministro, ao dirigir em momento tão decisivo, por mais de cinco anos, o Departamento Nacional de Saúde (1937-1939/1941-1945) ${ }^{12}$.

Sua vida profissional envolveu também atividades no campo acadêmico e na docência. No início dos anos 1920, foi professor de Medicina Legal da Faculdade de Medicina do Paraná; foi secretário geral dos $4^{\circ}$ e $5^{\circ}$ Congressos Brasileiros de Higiene; membro fundador e presidente honorário da Repartição Sanitária Panamericana (1942-1946). Foi também professor de Higiene da Faculdade de Medicina do Rio de Janeiro, da Faculdade Fluminense de Medicina e da Faculdade de Ciências Médicas do Rio de Janeiro ${ }^{12}$.

Barros Barreto presidiu a 11 ${ }^{\text {a }}$ Conferência Sanitária Panamericana, realizada no Rio de Janeiro, em 1942. Um evento que contou com a participação das principais lideranças da saúde pública brasileira e, sob o enquadramento da II Grande Guerra, representou um marco na produção de enunciados favoráveis à defesa continental por intermédio das ações de saúde. A defesa da cooperação em saúde, de modo a promover uma melhor integração entre estruturas e serviços de saúde militares e civis, foi uma das orientações legadas pelo evento ${ }^{13,14}$.

Além de membro da Academia Nacional de Medicina, Barros Barreto foi membro da Academia de Medicina de Lima e do México e da Sociedade Argentina de Medicina Social. Recebeu inúmeros prêmios e honrarias, entre elas a 
medalha de ouro Oswaldo Cruz, concedida pelo Instituto Oswaldo Cruz. Em 1950, cerca de seis anos antes de sua morte, receberia a comenda da Ordem Nacional do Mérito, uma condecoração concedida pelo Estado brasileiro somente àquelas pessoas reconhecidas pelas suas grandes contribuições ao país ${ }^{12}$.

Quando assumiu a direção do Departamento Nacional de Saúde, em 1937, Barros Barreto já era um sanitarista maduro e consagrado. Na altura dos seus 47 anos de idade, tinha vivido tempo suficiente para acompanhar e ser um operador, de relativo destaque, de mudanças organizacionais na saúde que, no contexto dos anos 1920, revelavam-se ainda incipientes se tomarmos como referência o que viria adiante. Não estava sozinho, Barros Barreto era parte de uma nascente comunidade de especialistas em administração da saúde pública, juntava-se a diferentes gerações de pesquisadores e especialistas, como Geraldo de Paula Souza, Rodolfo Mascarenhas, Francisco Borges Vieira, José Paranhos Fontenelle, Mario Pinotti, Aquiles Scorzelli, Claudio Magalhães da Silveira, Virgilio Correia, Alfredo Bica e outros ${ }^{9,12}$.

A este respeito, há que se pensar o período Vargas (1930-1945) como uma fase que, em boa medida, se cristalizam orientações e tendências anteriores, mas também como um período em que novas ideias e propostas ganharam contornos institucionais mais precisos e marcantes. No terreno das experiências que conformariam os debates sobre organização dos serviços de saúde, por exemplo, as décadas que se seguem a 1930 parecem-nos, neste ponto, decisivas.

O fato é que a Saúde, como um setor administrativo, não ficou imune às orientações e tendências mais gerais do período Vargas, sobretudo no que concerne à centralização político-administrativa e à formatação de uma "cultura técnica" acerca dos assuntos da administração. Tal cultura considerava uma desejada separação entre Administração e Política, de modo que, mediante a introdução de mecanismos burocráticos na Administração Pública, se promoveria uma necessária condução "técnica" e apolítica dos processos decisórios do Estado ${ }^{15-18}$. Hochman, por exemplo, chega a referir a reforma conduzida por Barros Barreto como uma espécie de "atualização" da organização da saúde pública aos preceitos político-organizacionais mais gerais do Estado brasileiro ${ }^{3}$.

Tal "atualização", contudo, não fez da administração da saúde pública um epifenômeno da organização geral do Estado. Há que se considerar as tendências já estabelecidas no debate e nas realizações do setor, bem como as orientações específicas, inclusive em suas conexões internacionais; as controvérsias e a emergências de noções e conceitos que, no terreno da saúde pública, teriam vigência longa. Há que se considerar, em resumo, as especificidades do debate organizacional em saúde.

\section{O debate organizacional brasileiro em saúde: ideias e propostas}

No terreno estritamente do que chamaríamos hoje de "organização dos serviços de saúde", as diferentes gerações de sanitaristas brasileiros que atuaram nos anos 1920 e 1930, em parte ancorados na experiência internacional, especialmente da Fundação Rockefeller, foi protagonista da defesa do atendimento às necessidades de saúde locais baseado em centros de saúde de ação integral e permanente; da ênfase na educação sanitária e do desenvolvimento de ações compatíveis com a noção de promoção à saúde; da valorização da base multiprofissional dos serviços; da ação sanitária disseminada por agentes de saúde visitadores e da atuação em tempo integral dos profissionais ligados a pesquisa e ao ensino em saúde ${ }^{19,20}$.

Àquela altura, por meio de bolsas de estudo, distintos sanitaristas brasileiros já registravam formação profissional nos Estados Unidos. Havia, por assim dizer, uma elite de médicos-sanitaristas que, a partir dos anos 1930, construiriam, gradualmente, uma arena de problemas acerca do que ficou conhecido como "a questão organizacional da saúde pública”, em boa medida, como dissemos, em sintonia com uma tradição rockefelleriana ${ }^{19,21-23}$.

Ocorre que os anos 1930 e 1940 representaram uma fase da história brasileira - e até certo ponto global - em que o debate organizacional ganhou inegável musculatura. A ideia de que o Estado deveria ser objeto de uma "organização", que lhe atribuísse maior racionalidade e eficiência, pautou condutas de diversos atores ${ }^{15-18,24,25}$. Tal ideia ganhou destaque e importância, em boa medida, porque foi habilmente conduzida por pessoas que reuniram tanto capacidade de produzir conhecimento sobre o assunto quanto de compartilhá-lo com seus contemporâneos. Barros Barreto, assim como outros personagens de seu tempo, pela importância que adquiriu na produção de ideias e conhecimentos, pelo destaque de suas posições institucionais e envergadura dos projetos que idealizou e implementou, coloca-se como personagem importante num processo de definição dos termos do debate organiza- 
cional em saúde e, a partir deles, na conformação de uma subárea de imensa ebulição intelectual no campo da saúde pública de sua época.

A rigor, Barros Barreto não manejava àquela altura questões de todo novas. A reformada saúde pública de 1906, bem como a reforma paulista dos anos 1920, já lidavam com a ideia de distritalização, então compreendida como o fatiamento do território e da autoridade estatal em regiões de saúde ${ }^{19}$. Além da conformação de enfoques e aparatos institucionais afinados com um discurso que impunha uma hegemonia da "técnica" na formulação de políticas, a novidade, por assim dizer, dizia respeito à organização nacional das instituições de saúde sob a coordenação de centros de saúde. O centro de saúde, portanto, se apresentava, em âmbito nacional, como a figura institucional nucleadora da organização sanitária? .

Sendo assim, parece-nos que os desafios para a implantação da política giraram mais entorno do conjunto de suas proposições, pela primeira vez organizadas na forma de um pacote potencialmente orgânico e nacional, do que propriamente pelo ineditismo de sua agenda.

Nessa linha, Rodolfo Mascarenhas ${ }^{26}$ nos chama a atenção que, ainda que Barros Barreto tenha permanecido por apenas 4 meses à frente dos serviços de São Paulo, ele teria sido o real responsável pela organização do departamento de saúde do Estado, provendo-o de centros de saúde e, pela primeira vez, prevendo a existência do cargo de visitador sanitário. Por essa mesma razão, Bertoldo Arruda $^{12}$ sugere que a embrionária experiência paulista permitiu à Barros Barreto uma maior clareza quanto à relação entre os centros de saúde e a chamada organização distrital no Brasil, em especial sobre o papel institucional do centro no território em que este se insere e também sobre a possibilidade de se desenvolver um vigoroso trabalho de educação sanitária nucleado nos centros e postos de saúde.

Trabalhos assinados por Paula Souza e por Borges Vieira revelam que a estratégia da educação sanitária se prestava, por intermédio das atividades dos centros de saúde, ao objetivo central de ampliar a cobertura assistencial para todo o território de saúde ${ }^{27}$. Ainda que não vedasse ações consideradas necessárias no terreno da cura e reabilitação, o centro se voltava, com especial atenção, para a execução de tarefas no campo da prevenção e da saúde pública: educação sanitária, com foco nas visitas domiciliares; estatística sanitária; monitoramento e ações nas populações adultas, gestantes e puericultura.
O que mais chama a atenção neste conjunto de proposições é a defesa de uma determinada "racionalidade" que apela para noções de eficiência e economia. Um arranjo institucional e organizacional cuja promessa é de maximização do uso dos recursos materiais e humanos em prol de resultados sanitários supostamente mais promissores. O cuidado com a tomada de decisões com base em dados estatísticos, por exemplo, é parte das ideias-força daquele ambiente 9 .

Será sob a notável posição institucional de chefe do DNS que Barros Barreto não apenas reuniria condições de implementar políticas alinhadas com as "novas ideias", mas, especialmente, desenvolvê-las, agora organizadas em um corpus técnico-doutrinário mais orgânico e, pela primeira vez, com alcance verdadeiramente nacional.

Nessa linha, Mello ${ }^{5,28}$ nos chama a atenção para o vocabulário que emergirá, a partir daí, com crescente mobilização de atores no campo da saúde pública: "coordenação", "distrito", "saúde coletiva", "tempo parcial e integral", "exame médico periódico", "generalidade" (em oposição à especializado), "descentralização", "visita domiciliária" e "comunidade". No seu conjunto, tal vocabulário tanto apontava para uma prática médica necessariamente menos centrada no indivíduo e mais articulada aos demais profissionais e à comunidade, quanto implicava num modelo organizacional de base territorial, cujo foco recairia nas ações preventivas e de saúde pública.

\section{A Reforma Capanema}

Em meados de 1934, Gustavo Capanema assume a direção do Ministério da Educação e Saúde Pública (MESP). Antes dele três diferentes ministros haviam conduzido a pasta sem que mudanças importantes fossem, de fato, realizadas, entre eles Washington Pires, médico mineiro que conduzia o ministério desde 1932 e a quem coube, segundo nos conta Arruda ${ }^{12}$, o processo inicial de formulação da reforma para a saúde. Até a data de posse de Capanema, o MESP correspondia, portanto, essencialmente, à estrutura administrativa do antigo Departamento Nacional de Saúde Pública (DNSP), criado no contexto da Reforma Sanitária da Primeira República ${ }^{3}$.

Menos de um ano após assumir o Ministério, Capanema propõe uma reforma geral na organização da saúde pública nacional. Seu primeiro ato, posto em prática com base na já mencionada Lei $n^{\circ} 378$, de janeiro de 1937, envolveu uma vigorosa revisão na estrutura político-administrativa do 
Ministério, a partir de então denominado Ministério da Educação e Saúde (MES). O segundo movimento viria em 1941, quando o ministro se voltou mais especificamente para as ações de saúde.

$\mathrm{Na}$ condição de operador da política, Barros Barreto assumiu a direção do Departamento Nacional de Saúde em fevereiro de 1937, apenas um mês após o início da implementação da Reforma. Atente-se que o DNS era o órgão responsável pela formulação e execução da reforma da saúde. Não é exagero, portanto, concluir que o médico carioca assumia a liderança do órgão responsável pelo redesenho mais importante da organização da saúde pública naqueles anos 1930 e 1940.

Barros Barreto revelou-se empolgado e genuíno defensor da organização do território brasileiro em oito grandes regiões de saúde ${ }^{12}$. Em cada uma delas, como previa a Lei no 378 , uma autoridade sanitária institucionalizada na forma de uma Delegacia Federal de Saúde. As Delegacias, por sua vez, tinham como função supervisionar as atividades relativas à colaboração da União com os serviços locais de saúde pública e assistência médica, inclusive com instituições privadas ${ }^{3}$. Representavam, portanto, uma forma de o governo Federal, instituindo padrões e mecanismos de fiscalização, se fazer presente em diferentes regiões do território nacional' ${ }^{9}$.

A Reforma, por assim dizer, instituía, de modo inédito, uma forma de descentralização e regionalização da gestão da saúde pública nacional. Ainda que os padrões de organização do aparato de saúde pública fossem objeto de formulação dos técnicos federais, a execução, a operação das políticas e orientações técnicas deveriam estar em afinidade com os arranjos políticos e necessidades definidas localmente. Daí a importância de instâncias como as Conferências Nacionais de Saúde. Para Barros Barreto:

Não era, de fato, prático e quiçá mesmo pouco realizável, em território extenso, como é o brasileiro, centralizar a administração sanitária. Mais se deve cuidar de tê-la coordenada e de procurar conseguir fixar normas técnicas gerais, com a necessária amplitude para adaptá-la às exigências e possibilidades locais ${ }^{8}$.

Em artigo publicado com José Paranhos Fontenelle ${ }^{29}$, em 1935, Barros Barreto compreendia que a "descentralização ou divisão distrital" deveria ser pensada como uma "forma mista, a da descentralização sem excesso". A rigor, o chefe do DNS se revelava um entusiasta do modelo norte -americano, em suas palavras:

Nos Estados Unidos, onde a norma é dar-se grande autonomia às organizações locais, vai sen- do defendida a doutrina da maior amplitude de comando para as organizações estaduais ${ }^{8}$.

Não se trata, contudo, de um mero transplantar de um arranjo estrangeiro à realidade brasileira. Considerando o cenário nacional, por "local", Barros Barreto entendia que:

Possam cada vez mais, com esse tipo de organização, o comando e a execução para a repartição estadual, ao invés de tê-la apenas como órgão de orientação, de controle e como centro de fornecimento de recursos técnicos e materiais para as organizações municipais. É a fórmula que mais se adapta ao Brasil... ${ }^{10}$.

Adicionalmente, em texto dirigido ao ministro, publicado em 1939, Barros Barreto adverte que a reforma não deveria ser "estereotipada" como uma mera iniciativa de organização dos "serviços básicos de saúde pública" nos estados. Em sua compreensão, ela conferia "bases modernas [ao] aparelhamento sanitário", na forma do estabelecimento de cooperação do DNS com os estados para o desenvolvimento de várias iniciativas, entre elas cursos e concursos para técnicos locais, formação de guardas e visitadoras sanitárias, instalação de laboratórios e levantamento de dados estatísticos?.

Cabe, assim, sinalizar que a centralização político-administrativa, há muito popularizada pela literatura que trata da gestão Vargas, não deve ser compreendida como um movimento centralizador tout court ou, em outras palavras, como um recurso que representou mera imposição da vontade do governante central e o consequente desprezo aos interesses das elites e lideranças locais. Tanto essa imagem não corresponde à realidade que para que seja possível compreendermos o real alcance da reforma conduzida por Barros Barreto torna-se necessário um olhar atento aos fóruns que permitiram determinada concertação inter-elites, sinal de que a centralização - até certo ponto - foi fruto de um entendimento entre lideranças. Tal entendimento, por sua vez, tornou possível a construção de aparatos organizacionais que ramificaram iniciativas, programas e políticas estatais no território nacional. O modelo organizacional de saúde do tipo distrital é, sem dúvida, parte deste processo.

Como partes essenciais da engenharia institucional da Reforma, criaram-se duas instâncias técnico-políticas cuja longevidade, ainda que com significativas mudanças, revela o papel estruturante do empreendimento administrativo pensado por Barros Barreto. A criação de um colegiado de técnicos, com caráter consultivo e normativo, convocado pelo ministro toda vez que o 
estabelecimento de normas, diretrizes e pareceres técnicos se fizessem necessários, revela o lugar que teria o discurso e a valorização da "técnica" na tomada de decisão nos assuntos da saúde. Com o nome de Conselho Nacional de Saúde, tal formato só seria modificado mais de 50 anos depois, quando o Decreto no 99.438/1990 introduziria uma série de alterações em seu papel institucional, passando, desde então, a desempenhar formalmente função deliberativa, além de envolver diversos segmentos da sociedade organizada.

Já a segunda instância, por convocação do Presidente da República, estabelecia a organização periódica de conferências nacionais de saúde, em prazo máximo de dois anos, com o propósito de promover um maior conhecimento do governo federal dos assuntos relativos à saúde púbica no âmbito dos estados federativos. Concebidas, igualmente, como "fóruns técnicos", as conferências representavam, nos termos de seu discurso oficial, oportunidade para se orientar a concessão de auxílio e apoio federal às políticas e iniciativas realizadas em âmbito local ${ }^{30}$.

Em que pese a existência de uma poderosa retórica em torno de um papel apolítico no emprego da "técnica" nas ações de saúde por parte de Barros Barreto e demais operadores da reforma, Fonseca $^{6}$ nos chama a atenção que o Conselho e as conferências nacionais de saúde representaram, na prática, a constituição de fóruns políticos em que o processo de centralização e normatização federal foi conduzido e, até certo ponto, negociado junto às lideranças locais.

A convocação da primeira conferência nacional de saúde só se daria, mediante o Decreto no 6.788, no final de janeiro de 1941. Na Exposição de motivos considerou-se as conferências como "órgãos destinados a promover o permanente entendimento [do] Ministério com os governos estaduais" 30 . Tudo isto nos faz pensar que o aprofundamento da centralização político-administrativa, que tanto caracterizou a gestão Vargas, como também a atualização da organização da saúde a estas mesmas orientações, só foram possíveis graças à implementação de fóruns de "entendimento" político que, ao fim e ao cabo, viabilizaram a organização de um modelo organizacional capilarizado, cuja base de operação era o território geográfico brasileiro.

Tal modelo organizacional, no corpo da reforma compreendido como "distrital", passava necessariamente pelo centro de saúde ${ }^{8-10,12}$. Suas funções, já segundo projeto de Paula Souza, Borges Vieira e Barros Barreto, estavam circunscritas às ações médico-sanitárias e organizacionais. No que diz respeito às primeiras, os centros lançavam-se prioritariamente sobre os problemas sanitários mais em evidência, tratando doentes, produzindo inquéritos, estatísticas e estudos científicos. Além de ações de reabilitação, desenvolviam atividades que diziam respeito à "conservação da saúde coletiva" ${ }^{27}$. Na experiência brasileira, portanto, os centros de saúde foram pensados para atuar nas frentes assistencial e de saúde pública. Segundo seus idealizadores:

Essa separação [assistência e saúde pública] não deve ser absoluta quanto aos métodos, pois a medicina clínica e as obras de prevenção não são antagônicas nem diferentes entre si, mas devem colaborar mutuamente em tudo que tenha por finalidade a melhoria da saúde da coletividade humana ${ }^{27}$.

Portanto, ainda que figuras como Barros Barreto concebessem diferentes papéis institucionais para a assistência e a saúde pública, ao fim e ao cabo, eles compreendiam que deveria haver uma estreita colaboração entre as atividades de saúde pública e as de assistência médica.

Tendo em vista tais expectativas, o trabalho médico, como era de se esperar, também deveria se organizar sob novas bases. Nas palavras de Paula Souza e Vieira:

O médico que vai fazer parte de um serviço desta natureza, por força do objetivo visado, não poderá atuar como o faria na clínica privada, hospitalar ou dispensários, e sim, revestir-se da consciência de higienista, tendo em mira a preservação da saúde dos matriculados e não o tratamento de males que não repercutam na coletividade ou descendência, pois, de outra forma, prejudicaria a função da organização ${ }^{27}$.

É preciso enfatizar alguns pontos especialmente importantes no documento acima. Quando se trata de estabelecer a diferença esperada na prática profissional de médicos no âmbito do exclusivo exercício da clínica e no trabalho exercido na saúde pública é logo mobilizada a ideia de "consciência higienista”, cujo exercício envolveria tanto a "preservação da saúde dos matriculados" quanto o "tratamento dos males" de alcance coletivo. O primeiro ponto remete, ainda que primariamente, ao desenvolvimento de ações de prevenção e promoção. Mas há, para estas ações, logo embutida uma noção de território e abrangência, pois a "preservação" da saúde não se dá de forma abstrata, mas envolve ações concretas em um dado contingente populacional definido, aquele dos “matriculados”. A noção de território de abrangência, portanto, pilar da organização distrital, se encontra referida no exercício do trabalho profissional. 
O segundo ponto, que trata dos males de alcance coletivo, remete a uma modalidade de trabalho profissional cujo foco é, por meio do tratamento e preservação da saúde dos indivíduos de um dado território, a melhoria constante e permanente das condições gerais de vida e de saúde. A dimensão coletiva do exercício do trabalho materializa-se na oferta de serviços e na capacidade coordenadora do centro em sua região. Tal "capacidade coordenadora" se expressaria, no contexto da Reforma Capanema, no que se refere à conduta profissional, por exemplo, na já comentada operação de um "sistema de cartas entre clínicos", mecanismo imaginado para promover a coordenação do consumo de produtos e serviços de saúde e à troca de informações clínicas sobre a situação de saúde das pessoas ${ }^{10}$.

Salienta-se que a dimensão coletiva do trabalho profissional se encontra especialmente preservada, notadamente no âmbito de atuação da visitadora sanitária, com o foco não no cuidado de saúde individual, mas na família como unidade de cuidado essencial.

As bases tanto de um papel institucional inovador, concebido para o centro de saúde, quanto de desempenho e organização do trabalho profissional para seus trabalhadores estavam claramente lançadas no contexto dos anos 1920-1940 e se pode dizer com boa dose de segurança que tal papel passou pela mente inquieta de figuras como Barros Barreto, Paula Souza, Borges Vieira e outros personagens.

No que tange propriamente à dimensão organizacional, os centros teriam um papel na coordenação de serviços, uma vez que "serviços de assistência médica ou sanitária em grandes comunidades, se não forem coordenados, trazem, geralmente, dificuldades" ${ }^{27}$. Mas que dificuldades seriam evitadas com a implantação de centros de saúde distritais?

O primeiro deles é a duplicação de esforços. A ideia de que, dentro de um determinado território, deveria haver alguma racionalidade tanto na oferta e prestação dos serviços quanto no consumo de serviços é a base do pensamento distrital. Nessa linha, cada instituição deveria cumprir um papel em um "sistema" funcional que previa a existência de instituições de atendimento geral e especializado. Atente-se que, como premissa, a ideia do que convencionamos chamar de uma organização sistêmica não era monopólio dos defensores dos centros de saúde e da organização distrital. No terreno hospitalar, a Divisão de Organização Hospitalar (DOH) do Departamento Nacional de Saúde (DNS) não só defendia uma necessária profissionalização dos gestores hospitalares, mas também uma forma de organização que instituísse racionalidade no fluxo de usuários entre os hospitais e entre estes e os centros de saúde, dispensários e outros organismos ${ }^{31}$.

Uma segunda dificuldade que seria enfrentada com a implantação de centros de saúde distritais envolvia a carência de informações sobre a realidade sanitária. Nesse sentido, o centro seria também o organismo capaz de centralizar, organizar e produzir estatísticas vitais, inquéritos e estudos capazes de permitir uma melhor compreensão acerca da realidade médico-sanitária no escopo do distrito. A ideia de que o trabalho em saúde deveria, portanto, ser subsidiado por informação qualificada já estava igualmente colocada.

Nos primeiros anos da década de 1940, em termos práticos, os centros de saúde tinham um alcance territorial que não era modesto nas capitais. Em Salvador, por exemplo, registramos três centros de saúde distritais; em Recife, quatro centros; no Distrito Federal, sob a batuta de Barros Barreto, doze centros; em São Paulo, onde a experiência justamente se iniciou, três.

No entanto, se considerarmos os níveis populacionais de cobertura imaginados em cada distrito (100.000 a 150.000 habitantes $)^{28}$, pode-se concluir que a extensão dos centros de saúde sobre o território nacional era bastante ambiciosa. O fato é que, nas circunstâncias da época, com fortes limitações de comunicação e transporte, não nos parece sensato imaginar que a função dos centros de saúde, tal como descrita acima, fosse desempenhada satisfatoriamente. Mas esse é um ponto que não só foge aos objetivos deste texto quanto é carente de estudos históricos que permitam, de fato, aquilatar a relação entre as ideias e propostas em tela ou sua real implantação em políticas efetivas naquele período.

Para aquilo que nos interessa, pode-se inferir, diante de tudo que dissemos, que no contexto dos anos 1930-1940, com um certo alcance, Barros Barreto foi um construtor com elevado nível de protagonismo na elaboração de ideias e propostas acerca da organização da saúde pública brasileira. Pode-se, ainda, especular acerca da importância de suas ideias, especialmente aquelas assentadas na noção de território e num papel protagonista do centro de saúde, como contribuições para um pujante e não linear processo de construção do campo da administração e organização dos serviços de saúde no país. Um movimento que, certamente, envolveu estas e outras gerações de sanitaristas brasileiros, da qual Barros Barreto é, sem sombras de dúvida, uma importante referência. 


\section{Considerações finais}

Se compreendermos, em nossos dias, a Saúde Coletiva, tal como ela se autorrefere, como uma espécie de ponto de confluência entre as ciências humanas e sociais, a epidemiologia e também a gestão e o planejamento, seremos capazes de percebera importância das contribuições seminais das gerações de sanitaristas que atuaram nos anos 1930-1940, em particular de Barros Barreto, para a conformação de uma trajetória de debate e realizações no campo da administração dos serviços de saúde.

Nesse ponto, convém reconhecer a trajetória de Barros Barreto tanto como um protagonista de um conjunto de medidas que produziram transformações concretas na forma como se organizava a saúde pública em todo o território nacional, mas também como um personagem que produziria mudanças na modalidade de discurso e racionalidade que conformaram práticas. As noções, conceitos e racionalidade que ampararam a reforma por ele conduzida foram também discutidas no texto como uma forma de tentar trazer alguns elementos para a construção de uma história do pensamento organizacional em saúde. Deste modo, apresentamos João de Barros Barreto como um dos construtores das bases teóricas e das iniciativas que, em outros cenários, diversos atores e lideranças se debruçarão, ora adensando entendimentos e orientações; ora introduzindo modificações e rupturas conceituais e de enfoque. Eis, portanto, uma história que se define pelas suas diferentes camadas e certamente pelas suas muitas cabeças pensantes.

É importante sinalizar para alguns aspectos importantes. O primeiro deles é que, com isso, não queremos afirmar que as "bases" construídas por Barros Barreto e seus apoiadores foram uma espécie de marco-zero de um processo linear cujo desfecho seria, décadas depois, a proposição do sistema de saúde vigente, por exemplo. Significa dizer, em termos históricos, que o diretor do DNS foi capaz de construir, com os recursos técnicos e tecnológicos que se podia contar à sua época, uma reforma que procurava responder à problemática da saúde de seu tempo. Qual problemática? Essencialmente, como ampliar a cobertura assistencial e enfrentar os problemas de saúde mais prevalentes, mobilizando abordagens organizacionais que permitissem os melhores resultados com o emprego de menos recursos.

Outro ponto que merece reflexão diz respeito ao papel daquilo que aqui chamamos de "bases" para a compreensão das ideias, práticas, processos e inovações promovidas pela Reforma Capanema. Como discutimos ao longo do texto, a reorganização da saúde pública no contexto da reforma conduzida por Barros Barreto sistematizou e mobilizou, pela primeira vez, com alcance nacional, uma série de abordagens e noções organizacionais. Coordenação dos serviços, abordagem distrital, território de saúde, formação profissional com foco em "generalistas", descentralização e capilarização, visita domiciliária e foco na família e na comunidade são algumas das concepções-chave que passaram a habitar, de forma mais sistemática, os escritos e as preocupações dos sanitaristas. Desde então mobilizamos essas mesmas categorias com o mesmo sentido e alcance? Parece-nos incorreto afirmar que a Reforma Capanema seja uma espécie de marco-zero de um debate que, em diferentes contextos e sempre contando com diferentes personagens, ganhará novas orientações e perspectivas doutrinárias e conceituais.

Barros Barreto, pela complexidade de suas ideias e extensão de suas iniciativas, moveu longevos moinhos e diversos atores não necessariamente comprometidos com o processo que, originariamente, ele conduziu. Diferentes correntes do debate da saúde pública repercutiram, cada qual movendo aquilo que interessa, a expertise e o conhecimento que envolveu tanto a implantação de uma renovada engenharia institucional para a organização da saúde quanto questões que envolvem o exercício do trabalho profissional. 


\section{Referências}

1. Schwartzman S, Bomery HMB, Costa VMR. Tempos de Capanema. Rio de Janeiro: Paz e Terra/FGV; 2000.

2. Cunha LA. A universidade temporã: o ensino da colônia à era Vargas. Rio de Janeiro: Francisco Alves; 1986.

3. Hochman G. Reformas, instituições e políticas de saúde no Brasil (1930-1945). Educar Rev 2005; 25:127141.

4. Campos AV. Políticas internacionais de saúde na Era Vargas: o Serviço Especial de Saúde Pública, 1942-1960. Rio de Janeiro: Ed. Fiocruz; 2006.

5. Mello GA. Pensamento clássico da saúde pública paulista na era dos centros de saúde e educação sanitária. Rev Saude Piblica 2012; 46(4):747-750.

6. Fonseca CMO. Saúde no Governo Vargas (1930-1945). Dualidade institucional de um bem público. Rio de Janeiro: Ed. Fiocruz; 2007.

7. Costa WGA, Moeda ST. Repensando a rede básica de saúde e o distrito sanitário. Saude Debate 2001; 15(57):15-29.

8. Barros Barreto J. Saúde Pública no Brasil. Arquivos Higiene 1938; 8:289-304.

9. Barros Barreto J. Serviços Federais de Saúde em 1938. Exposição apresentada ao Exmo. Ministro da Educação e Saúde pelo Diretor Geral do Departamento Nacional de Saúde. Rio de Janeiro: DNS/MÊS; 1939.

10. Barros Barreto J. Normas para uma organização estadual de saúde pública. Arquivos Higiene 1937; 2:341370.

11. Lima NT, Fonseca CMO. História da especialização em saúde pública no Brasil: nota introdutória. Lima NT, Fonseca CMO, Santos PRE, organizadores. Uma escola para a saúde. Rio de Janeiro: Editora Fiocruz; 2004.

12. Arruda BKG. João de Barros Barreto. In: Separata dos Anais da Academia Pernambucana de Medicina; 1974.

13. Hochman G, Fonseca CA. I Conferência Nacional de Saúde: reformas, políticas e saúde em debate no Estado Novo. In: Gomes AC, organizador. Capanema: o ministro e seu ministério. Rio de Janeiro: Fundação Getúlio Vargas; 2000. p. 173-194.

14. Lima NT. O Brasil e a Organização Pan-Americana da Saúde: Uma história em três dimensões. In: Filkelman J, organizador. Caminhos da saúde pública no Brasil. Rio de Janeiro: Editora da Fiocruz; 2002. p. 24-116.

15. Cunha MWV. O sistema administrativo brasileiro (1930-1950). Rio de Janeiro: Instituto Nacional de Estudos Pedagógicos; 1963. (Série VI, Sociedade e Educação. Coleção O Brasil Urbano).

16. Graham LS. Civil service reform in Brazil: principles versus practice. Texas: University of Texas Press; 1968.

17. Wahrlich BS. Reforma administrativa na era Vargas. Rio de Janeiro: Ed. Fundação Getúlio Vargas; 1983.

18. Mattos Dias JL. Os engenheiros do Brasil. In: Gomes AC. Engenheiros e economistas: novas elites burocráticas. Rio de Janeiro: FGV; 1994.
19. Faria LR. Saúde e Política: A Fundação Rockefeller e seus parceiros em São Paulo. Rio de Janeiro: EdItora Fiocruz; 2007.

20. Catro-Santos LA, Faria LR. Os primeiros Centros de Saúde nos Estados Unidos e no Brasil. Teoria Pesquisa 2002; 40-41:137-181.

21. Campos CEA. A organização dos serviços de Atenção Primária à Saúde no Brasil. Rev Bras Med Familia Comuni 2006; 2(6):131-147.

22. Teixeira LA. Comentário: Rodolfo Mascarenhas e a história da saúde pública em São Paulo. Rev Saude Publica 2006; 40(1):3-19.

23. Teixeira LA. Rodolfo dos Santos Mascarenhas: pioneiro da história da saúde. Cien Saude Colet 2015, 20(4):1135-1141.

24. Blau PM. The Dynamics of bureaucracy. A study of interpersonal relations in two government agencies. Chicago: The University of Chicago Press; 1963.

25. Crozier M. O fenômeno burocrático. Brasília: Ed. Universidade de Brasília; 1981. (Coleção Sociedade Moderna, vol. 2).

26. Mascarenhas R. História da Saúde Pública no Estado de São Paulo. Rev Saude Publica 2006; 40(1):3-19.

27. Souza GHP, Vieira FB. Centro de Saúde: eixo da organização sanitária. São Paulo: Instituto de Higiene de São Paulo/Escola de Higiene e Saúde Pública do Estado; 1944.

28. Mello GA. Revisão do pensamento sanitário como foco no Centro de Saúde [tese] São Paulo: Faculdade de Medicina da Universidade de São Paulo; 2010.

29. Barreto JB, Fontenelle, JP. O systema dos centros de saúde no Rio de Janeiro. Archivos Hygiene 1935; 5(1):83-115.

30. Brasil. Ministério da Educação e Saúde (MES). Serviço Nacional de Documentação (SND). I Conferência Nacional de Educação e I Conferência Nacional de Saúde. Rio de Janeiro: MES/SND; 1941.

31. Brasil. Ministério da Saúde (MS). Departamento Nacional de Saúde (DNS). Divisão de Organização Hospitalar (DOH). História e evolução dos hospitais. Rio de Janeiro: MS/DNS/DOH; 1965.

Artigo apresentado em 22/08/2019

Aprovado em 08/06/2020

Versão final apresentada em 10/06/2020

Editores-chefes: Romeu Gomes, Antônio Augusto Moura da Silva 